\title{
Environmental and Organizational Factors Associated with Elbow/Forearm and Hand/Wrist Disorder among Sewing Machine Operators of Garment Industry in Ethiopia
}

\author{
Wakjira Kebede Deyyas ${ }^{1}$ and Ararso Tafese ${ }^{2}$ \\ ${ }^{1}$ Department of Medical Laboratory Sciences and Pathology, Collage of Public Health and Medical Sciences, \\ Jimma University, P.O. Box 378, Jimma, Ethiopia \\ ${ }^{2}$ Oromia Regional Social and Labour Affairs Agency, Addis Ababa, Ethiopia
}

Correspondence should be addressed to Wakjira Kebede Deyyas; dandiwk2004@gmail.com

Received 15 March 2014; Revised 9 June 2014; Accepted 1 August 2014; Published 15 September 2014

Academic Editor: Chit Ming Wong

Copyright (C) 2014 W. Kebede Deyyas and A. Tafese. This is an open access article distributed under the Creative Commons Attribution License, which permits unrestricted use, distribution, and reproduction in any medium, provided the original work is properly cited.

\begin{abstract}
Occupational health problems related to upper limp musculoskeletal disorders were the major issue among sewing machine operators of garment industries in Ethiopia. The aim of this study was to assess the prevalence and associated risk factors of work related elbow and wrist musculoskeletal disorders among sewing machine operators of garment industries in Galan City, Oromia Regional State. A cross-sectional study was conducted from April 1 to 30, 2012. A total of 422 study subjects were included in this study. Standard Nordic Musculoskeletal Questionnaire was used to collect detailed information on musculoskeletal symptom, sociodemographic data, and factors associated with the problems through face to face interview. From a total of 422 sewing machine operators included in the study $370(87.7 \%)$ were females and $306(72.5 \%)$ were in the age group of $<30$ years. The prevalence of self-reported work related elbow and wrist musculoskeletal disorders was $40 \%$ and $37.7 \%$, respectively. In multivariate analysis, those who had $>16$ years of service were about five times more likely to develop elbow and wrist musculoskeletal disorders than those who had short ( $1-5$ years) year of services [AOR $=4.7,95 \%$ CI: $1.55-13.02$ ], physical activities [AOR $=5.02,95 \%$ CI: $1.57-$ 16.00], and methods of payment [AOR $=2.01,95 \%$ CI: 1.23-3.28], factors significantly associated with this disorders. Work related elbow and wrist musculoskeletal disorders were high among sewing machine operators in selected garment industries. Moreover, personal and environmental factors were identified as the potential risk factors related to elbow and wrist musculoskeletal disorders among the study group. Therefore, government and the owner of the garment industries should give special attention to prevent and control the problems through proper occupational health and safety policy implementation in the country.
\end{abstract}

\section{Introduction}

Work related musculoskeletal disorders (WRMSDs) have been considered as the potential threats of major public health problems associated with unsafe work environments. The daily hardship cost of human is the burden of poor occupational safety and health practices that can cause pain and disability in the functions of upper body musculoskeletal systems. About 6,300 individuals were dying every day as a result of occupational work related problems in the world [1]. The issues of safety and health conditions at workplace were different between countries, organizational sectors, and social groups. For example, about 317 million accidents occur on the job annually, mostly which take a heavy toll in developing countries where thousands of poor and the least protected people were involved in sewing machine operator in garment industries [2].

WRMSDs among sewing machine operators of garment industries were a reason for long term sick leave and disability pensions in the world [3]. World Health Organization (WHO) reported 50-70\% individuals developed WRMSDs when exposed to poor working environments during working for the job [4]. A study conducted in Boston, America, showed that sewing machine operators had been highly affected by work related upper limb pain. Moreover, the United State Bureau of Labour Statistics Annual Survey of 
occupational injuries and illnesses ranked sewing machine operators of clothing industry in the country offering to upper body musculoskeletal disorders [5].

Study in Finland among office employees reported that female workers were more likely exposed to WRMSDs than male workers [5]. Moreover, Turkey and Denmark reported the years of service were significantly associated with elbow, wrist, and shoulder and neck musculoskeletal (MS) disorders among workers in garment industries [6-8]. In Denmark population the prevalence of MS symptoms of the neck, shoulders, back, and wrist among sewing machine operators were found to be $57 \%, 51 \%, 47 \%$, and $26 \%$, respectively [7]. Moreover, results from 11 factories from 7 sectors of manufacturing industry in South Africa exposed to poor design of working environments in the workplace were significantly associated with MS pain of the hand, elbow, neck, and shoulders [9].

Harmful inflammatory diseases that can cause pain and disability in the functions of elbows, arms, wrists, and hands experienced in the last 12 months were used as an outcome measure for this study. Therefore, prevention of WRMSDs among workforces may be a national priority in many countries. Even though an Ethiopian labour proclamation permits working in all types of industries for 8 hours per day or 48 hours per week [10], there is a lack of strong functioning health and safety system, particularly, among garment industries where workers are involved in sewing machine operating tasks in the study area.

This study aimed to assess the prevalence and associated risk factors of work related elbow/forearm and wrist/hands MS disorders among workers who were directly involved in operating sewing machine work in the selected garment industries in Galan City. The findings of this study will provide information on workplace illness and injuries in the garment industries and also have important public health implication by providing information for policy makers to design strategy to keep strong functioning health and safety system for people who become tackled by these problems.

\section{Materials and Methods}

2.1. Study Setting and Period. An institution based crosssectional study was conducted in two large garment industries selected in Galan City administration from April 1 to 30, 2012. Galan City is one of the industrial zones in Oromia Regional State, which is $25 \mathrm{KMs}$ far from Addis Ababa, the capital city of Ethiopia, in Eastern direction, where most of the foreign and domestic investors were investing in different industrial activities. Among these industrial activities, operating garment factories were the most common ones. Two large garment industries, owned by Ethiopians investors living outside Ethiopia, were selected for this study, each having 632 and 362 sewing machine operators, respectively.

2.2. Sample Size and Sampling Procedures. A total of 994 sewing machine operators who had worked in the two garment industries for more than 12 months prior to the study period were considered as source population. The sample size was determined using single population proportion formula and, to maximize the sample size, 50\% assumption was assumed at $95 \%$ confidence interval and margin of error $5 \%$. Therefore including 10\% nonresponse rate, the total sample size obtained was 422 . First, sewing machine operators were stratified by its organizational structure and then afterwards the sample size was proportionally allocated to each garment industry. Lottery method was used to recruit the actual number of study units. Administrative or supportive staff and workers who were absent during data collection period were excluded from the study.

2.3. Data Collection Process. Data were collected using a standardized Nordic questionnaire [11]. The questionnaire was translated from English into Amharic and then independently back-translated to English with adjustment of the Amharic version where problems were identified. The contents of the questionnaire included sociodemographic characteristics (sex, age, marital status, educational level, monthly salary, and years of service), personal factors (height and weight of participants were measured to calculate BMI, smoking behavior, habit of doing physical activity, medical history of systemic illness, and medical history of musculoskeletal disorder), organizational factors (payment method, work hours, employment status, break time excluding lunch, and health and safety training), and working environmental factors (job satisfaction, repetitive work within less than 30 seconds, doing too much work, availability of sufficient light, and availability of adjustable chair). At baseline, participants were asked about pains in the elbow/forearm and wrist/hand lasting for at least a day over the past 12 months and those who had reported pain at baseline over the past 12 months were determined.

2.4. Ethical Clearance. Ethical clearance was obtained from Oromia Regional Labour and Social Affairs Agency. A formal letter of cooperation was delivered to the owner of the garment industries. Verbal informed consent was obtained from each study participant after having been informed of the objective of the study.

2.5. Data Analysis and Interpretation. The collected data were edited, coded, and entered into SPSS version 20.0 software program for analysis. Bivariate logistic regression analysis was used to determine the effect of independent variables on the outcome variables and those variables with $P$ value $<$ 0.2 were exported to multiple logistic regression for further analysis [12], and the summary statistics such as mean, standard deviation, and percentage were used to describe the study population in relation to outcome variables. The degree of association between independent and dependent variables was assessed using odds ratio with $95 \%$ confidence interval.

\section{Results}

3.1. Sociodemographic Characteristics of Study Participants. A total of 422 sewing machine operators were included in the study and are with $100 \%$ response rate. Majority of the study 
subjects, $370(87.7 \%)$, were females. Most of the respondents, $306(72.5 \%)$, were in the age group of $<30$ years and the mean age of the study subjects was $26.9 \pm 7.2 \mathrm{SD}$. For marital status, $227(53.8 \%)$ were single and 145 (34.4\%) were married and $200(47.4 \%)$ had attended secondary school. Among the respondents, $270(64.0 \%)$ had served from 1-5 years and $23(5.3 \%)$ had served above 16 years and the mean years of service were 5 (with SD 5.27, minimum and maximum 1 and 30, resp.). Two hundred and fifty-two (59.7\%) were paid monthly salary of 700 to 900 Ethiopian birr or 35.5 to 45.5 US dollar and 138 (32.7\%) were paid below 700 Ethiopian birr or below 35.5 US dollar per month (Table 1).

3.2. Personal Characteristics of Study Participants. Body mass index of the respondents was calculated by measuring height and weight of the participants during data collection by trained nurses and $325(77.0 \%)$ subjects were being healthy $\left(18.6-24.9 \mathrm{~kg} / \mathrm{m}^{2}\right)$ and $4(0.9 \%)$ were obese $\left(>30 \mathrm{~kg} / \mathrm{m}^{2}\right)$ and the mean body mass index of the study subjects was $20.4 \pm$ 2.62 SD with minimum and maximum value of 13.5 and 31.25 , respectively. Three hundred and fifty-four $(83.9 \%)$ were not practicing physical exercise, $26(6.2 \%)$ were practicing more than three times per week. Three hundred and ninety-five (93.6\%) of the respondents were noncigarette smokers, 65 (15.4\%) were with medical history of MS disorders, and 43 (10.2\%) were with systemic illness (Table 2).

\subsection{Conditions of Working Environment of Sewing Machine} Operators. Almost half of the respondents, 204 (48.3\%), were not satisfied with their current job, 196 (46.4\%) of the respondents were always exposed to repetitive task with repeating the same task within 30 seconds, and 200 (47.4\%) of the respondents feel always doing too much work within working hour. Three hundred and seventy-one (87.9\%) of the respondents were having enough sufficient light to operate sewing machine, and $307(72.7 \%)$ of the operators were not using an adjustable chair (Table 3 ).

3.4. Organizational Factors of Sewing Machine Operators. Employment status of respondents, 397 (94.1\%), was permanent and the rest were temporary workers. Three hundred and thirty $(74.2 \%)$ of the operators' payment method was by means of hourly rate. Among 380 (90.0\%) of the workers who worked for 8 hours per day, $343(81.3 \%)$ of the workers were not having break (excluding lunch time). The majority of 405 (96.0\%) of the respondents had never attained training on the issue of ergonomic at workplaces (Table 4).

3.5. Prevalence of Elbow/Forearm and Hands/Wrist MS Disorders. The prevalence of work related elbow/forearm and hands/wrist MS disorders among sewing machine operators who had experienced trouble (ache, pain, and discomfort) in the last 12 -month period were $40 \%$ and $37.7 \%$, respectively. One hundred and sixty-nine $(40.0 \%)$ of the respondents had elbow/forearm MS disorders. Of these, 70 (16.6\%) had experienced ache, pain, and discomfort more than 30 days, but not every day. Of the total respondents, 159 (37.7\%) of the sewing machine operators developed hand/wrist MS
TABLE 1: Sociodemographic characteristics of study participants and year of service in garment industries in Galan City, Oromia Regional State, Eastern Ethiopia, 2012.

\begin{tabular}{|c|c|c|}
\hline Category of variable & Frequency $(n=422)$ & $(\%)$ \\
\hline \multicolumn{3}{|l|}{ Sex } \\
\hline Male & 52 & $(12.3)$ \\
\hline Female & 370 & $(87.7)$ \\
\hline \multicolumn{3}{|l|}{ Age (in years) } \\
\hline$>30$ years & 306 & $(72.5)$ \\
\hline $30-39$ years & 89 & $(21.1)$ \\
\hline $40-49$ years & 18 & $(4.30)$ \\
\hline$\geq 50$ years & 9 & $(2.10)$ \\
\hline \multicolumn{3}{|l|}{ Marital status } \\
\hline Married & 145 & $(34.0)$ \\
\hline Divorced & 29 & $(6.80)$ \\
\hline Widowed & 21 & $(5.00)$ \\
\hline Single & 227 & $(58.8)$ \\
\hline \multicolumn{3}{|l|}{ Educational level } \\
\hline Illiterate & 45 & $(10.7)$ \\
\hline Primary & 135 & $(32.0)$ \\
\hline Secondary & 200 & $(47.40$ \\
\hline Higher education & 42 & $(10.0)$ \\
\hline \multicolumn{3}{|l|}{ Monthly salary } \\
\hline$<700$ ETB $(<35.5$ US dollar $)$ & 138 & $(32.7)$ \\
\hline 700-900 ETB (35.5-45.5 US dollar) & 252 & $(59.7)$ \\
\hline$>900$ ETB (>45.5 US dollar) & 32 & $(7.60)$ \\
\hline \multicolumn{3}{|l|}{ Year of service in garment } \\
\hline Mean $( \pm S D)$ & $5( \pm 5.2)$ & - \\
\hline $1-5$ years & 270 & $(64.0)$ \\
\hline $6-10$ years & 118 & $(28.0)$ \\
\hline $11-15$ years & 11 & $(2.60)$ \\
\hline$\geq 16$ years & 23 & $(5.40)$ \\
\hline
\end{tabular}

disorders, of which 50 (11.8\%) had experienced pain and discomfort for more than 30 days (Table 5).

3.6. Factors Associated with Work Related Elbow/Forearm and Hand/Wrist MS Disorders. In bivariate logistic analysis, variables such as gender, educational level, monthly salary, year of service, habit of doing physical activities, employment status, payment method, and medical history of systemic illness were significantly associated with elbow/forearm MS disorders; however, after adjusting for the effects of other variables gender and monthly salary were independently associated with each other. Moreover, year of service, habit of doing physical activities, and payment methods were significantly associated with elbow/forearm disorders. Being males to be a risk for the problems than females $[\mathrm{AOR}=1.8$, 95\% CI: 1.7-4.8]. Those who had service of $>16$ years were about 5 times more likely to develop elbow/forearm disorder than those who had short (1-5 years) years of service $[A O R=$ 4.7, 95\% CI: 1.55-13.02].

Workers who did not have habit of doing physical activities were 5 times more likely to develop elbow/forearm 
TABLE 2: Personal factors associated with elbow and wrist MS disorder among sewing machine operators in garment industries in Galan City, Oromia Regional State, Eastern Ethiopia, 2012.

\begin{tabular}{lcc}
\hline Category of variable & Frequency $(n=422)$ & $(\%)$ \\
\hline BMI (body mass index) & & \\
Underweight $\left(<18.5 \mathrm{~kg} / \mathrm{m}^{2}\right)$ & 76 & $(18.0)$ \\
Healthy $\left(18.5-24.9 \mathrm{~kg} / \mathrm{m}^{2}\right)$ & 325 & $(4.1)$ \\
Overweight $\left(25-29.9 \mathrm{~kg} / \mathrm{m}^{2}\right)$ & 17 & $(0.9)$ \\
Obese $\left(\geq 30 \mathrm{~kg} / \mathrm{m}^{2}\right)$ & 4 & \\
Habit of doing physical activities & & $(83.9)$ \\
None & 354 & $(6.9)$ \\
Once per week & 29 & $(3.1)$ \\
Two times per week & 13 \\
$\geq$ Three times per week & 26 & $(6.2)$ \\
Smoking behaviour & & \\
Nonsmoker & 395 \\
Past smoker & 14 & $(3.6 .6)$ \\
Current smoker & 13 & $(3.1)$ \\
Medical history of MS disorders & & \\
Yes & 65 \\
No & 357 & $(15.4)$ \\
Medical history of systemic illness & & \\
Yes & 43 & \\
No & 379 & $(89.8)$ \\
\hline
\end{tabular}

TABLE 3: Working environmental factors associated with elbow and wrist MS disorders among sewing machine operators in garment industries in Galan City, Oromia Regional State, 2012.

\begin{tabular}{lcc}
\hline Category of variables & $\begin{array}{c}\text { Frequency } \\
(n=422)\end{array}$ & $(\%)$ \\
\hline Job satisfaction & 204 & $(48.3)$ \\
$\quad$ Not satisfied & 187 & $(44.3)$ \\
$\quad$ Somewhat satisfied & 31 & $(7.4)$ \\
$\quad$ Very satisfied & & \\
Repetitive work within $<30$ seconds & 13 & $(3.1)$ \\
$\quad$ Never & 96 & $(22.7)$ \\
Sometimes & 117 & $(27.7)$ \\
Often & 196 & $(46.5)$ \\
$\quad$ Always & & \\
Doing too much work & 8 & $(1.9)$ \\
$\quad$ Never & 123 & $(29.1)$ \\
Sometimes & 91 & $(21.6)$ \\
Often & 200 & $(47.4)$ \\
Always & & \\
Availability of sufficient light & 371 & $(87.9)$ \\
$\quad$ Yes & 51 & $(12.1)$ \\
$\quad$ No & & \\
Adjustable chair & 115 & $(27.3)$ \\
$\quad$ Yes & 307 & $(72.7)$ \\
$\quad$ No & &
\end{tabular}

disorder than those who had the habit of doing physical activities more than three times per week $[\mathrm{AOR}=5.02,95 \%$ CI: 1.57-16.00] and workers whose payment was via piece rate were 2 times more likely to develop elbow/forearm disorder than those paid through hourly payment $[\mathrm{AOR}=2.01,95 \%$
TABLE 4: Organizational factors associated with elbow and wrist MS disorders among sewing machine operators in garment industries in Galan City, Oromia Regional State, Eastern Ethiopia, 2012.

\begin{tabular}{lcc}
\hline Category of variables & $\begin{array}{c}\text { Frequency } \\
(n=422)\end{array}$ & $(\%)$ \\
\hline $\begin{array}{l}\text { Employment status } \\
\quad \text { Temporary }\end{array}$ & 25 & \\
$\quad$ Permanent & 397 & $(5.9)$ \\
Payment method & & \\
$\quad$ Hourly payment & 313 & $(74.2)$ \\
$\quad$ Piece rate payment & 109 & $(25.8)$ \\
Total working hours a day & & \\
$\quad 8$ hours & 380 & $(90.0)$ \\
$\quad 9-10$ hours & 25 & $(5.9)$ \\
$\quad>10$ hours & 17 & $(4.1)$ \\
Total working breaks excluding lunch & & \\
break & 42 & $(10)$ \\
$\quad \leq 15$ minutes & 37 & $(8.8)$ \\
$\quad>15$ minutes & 343 & $(81.2)$ \\
$\quad$ None & & \\
Training on issue of ergonomics & 17 & $(4.0)$ \\
$\quad$ Yes & 405 & $(96.0)$ \\
$\quad$ No &
\end{tabular}

CI: 1.23-3.28] (Table 6). Employees with longer years of service ( $\geq 16$ years) were 4 times more likely to develop hand/wrist disorder than those who had short (1-5 years) years of service $[\mathrm{AOR}=4.09,95 \% \mathrm{CI}$ : 1.48-11.24] (Table 7).

\section{Discussion}

Work related MS disorders were common problems in garment industries, especially among sewing machine operators in the study area. In the present study, the prevalence of selfreported elbow/forearm and hand/wrist MS disorders was $40 \%$ and $37.7 \%$, respectively. This finding was comparable with the studies done in UK and Finland where the prevalence of hand MS disorders was reported to be from 34 to $75 \%,[13,14]$. However, a study in Los Angeles, USA, showed that the prevalence of elbow hand/wrist was $16 \%$ [15]. This difference might be due to the difference of the study setting. In the USA the study was conducted on small shop sizes in which participants could mostly be the family or relatives of the shop owners and therefore they were not enforced to work for long time. However, this study was conducted on large scale industries in which workers were working for more than eight hours per day.

In this study, males sewing machine operators were more likely to develop elbow/forearm and hand/wrist disorders than females sewing machine operators $[\mathrm{AOR}=1.8,95 \%$ CI: 1.7-4.8] and [AOR $=2.9,95 \% \mathrm{CI}: 1.3-6.4]$, respectively. Studies conducted among Iranian sewing machine operators of shoe manufacturing showed that females were more at risk to develop elbow MS disorders [7, 16]. This difference might be due to the deference between the type of machines used in shoe manufacturing and garment industries. Additionally, males were interested to do work even during night time. 
TABLE 5: Prevalence of elbow/forearm and hands/wrist MS disorders among sewing machine operators in the last 12 months in garment industries in Galan City, Oromia Regional State, 2012.

\begin{tabular}{|c|c|c|}
\hline & \multicolumn{2}{|c|}{ Symptoms by anatomical body site } \\
\hline & Elbow/forearm disorder, $N(\%)$ & Hand/wrist disorder, $N(\%)$ \\
\hline \multicolumn{3}{|l|}{ Trouble in the past 12 months } \\
\hline Yes & $169(40.0)$ & $159(37.7)$ \\
\hline No & $253(60.0)$ & $263(62.3)$ \\
\hline \multicolumn{3}{|c|}{ Total length of MS disorder trouble } \\
\hline $1-7$ days & $34(8.1)$ & $37(8.8)$ \\
\hline $8-30$ days & $40(9.4)$ & $36(8.5)$ \\
\hline$>30$ days, but not every day & $70(16.6)$ & $50(11.8)$ \\
\hline Every day & $25(5.9)$ & $36(8.5)$ \\
\hline
\end{tabular}

TABLE 6: Multivariate analysis for factors associated with elbow/forearm MS disorders among sewing machine operators in Galan City, Oromia Regional State, Eastern Ethiopia, 2012.

\begin{tabular}{|c|c|c|c|c|}
\hline \multirow{2}{*}{ Category of variables } & \multicolumn{4}{|c|}{ Elbow/forearm disorder } \\
\hline & Yes $n(\%)$ & No $n(\%)$ & COR $(95 \% \mathrm{CI})$ & AOR $(95 \% \mathrm{CI})$ \\
\hline \multicolumn{5}{|l|}{ Sex } \\
\hline Male & $34(65.4)$ & $18(34.6)$ & $3.2(1.6-5.5)$ & $1.8(1.7-4.8)^{* *}$ \\
\hline Female & $135(36.5)$ & $235(63.5)$ & 1.00 & 1.00 \\
\hline \multicolumn{5}{|l|}{ Educational level } \\
\hline Illiterate & $17(37.8)$ & $28(62.2)$ & $0.55(0.23-1.29)$ & \\
\hline Primary school & $59(43.7)$ & $76(56.3)$ & $0.70(0.35-1.41)$ & \\
\hline Secondary school & $71(35.5)$ & $129(64.5)$ & $0.50(0.25-0.97)$ & \\
\hline Higher education & $22(52.4)$ & $20(47.6)$ & 1.00 & \\
\hline \multicolumn{5}{|l|}{ Monthly salary } \\
\hline$<700$ ETB $(<35.5$ US dollar $)$ & $34(24.6)$ & $104(75.4)$ & $0.17(0.07-0.39)$ & $0.21(0.08-0.54)^{*}$ \\
\hline 700-900 ETB (35.5-45.5 US dollar) & $114(45.2)$ & $138(54.8)$ & $0.43(0.20-0.93)$ & $0.47(0.19-1.13)$ \\
\hline$>900$ ETB (>45.5 US dollar) & $21(65.6)$ & $11(34.4)$ & 1.00 & 1.00 \\
\hline \multicolumn{5}{|l|}{ Year of service in garment } \\
\hline $1-5$ years & $93(34.5)$ & $177(65.5)$ & 1.00 & 1.00 \\
\hline $6-10$ years & $52(44.1)$ & $66(55.9)$ & $1.50(0.96-2.32)$ & $1.04(0.64-1.70)$ \\
\hline $11-15$ years & $6(54.5)$ & $5(45.4)$ & $2.28(0.67-7.68)$ & $1.50(0.39-5.77)$ \\
\hline$\geq 16$ years & $18(78.3)$ & $5(21.7)$ & $6.85(2.46-19.04)$ & $4.70(1.55-13.02)^{* *}$ \\
\hline \multicolumn{5}{|l|}{ Physical activities } \\
\hline None & $141(39.8)$ & $213(60.1)$ & $1.48(0.63-3.51)$ & $5.02(1.57-16.05)^{*}$ \\
\hline Once per week & $17(58.6)$ & $12(41.4)$ & $3.18(1.04-9.70)$ & $5.54(1.46-21.00)^{*}$ \\
\hline Two times per week & $3(23.0)$ & $10(76.9)$ & $0.67(0.14-3.13)$ & $0.59(0.10-3.49)$ \\
\hline$\geq 3$ times per week & $8(30.8)$ & $18(69.2)$ & 1.00 & 1.00 \\
\hline \multicolumn{5}{|l|}{ Medical history of systemic illness } \\
\hline Yes & $30(46.2)$ & $35(53.8)$ & $2.03(1.07-3.85)$ & \\
\hline No & $139(38.9)$ & $218(61.1)$ & 1.00 & \\
\hline \multicolumn{5}{|l|}{ Employment status } \\
\hline Temporary & $16(64.0)$ & $9(36.0)$ & $2.83(1.22-6.37)$ & \\
\hline Permanent & $153(38.5)$ & $244(61.5)$ & 1.00 & \\
\hline \multicolumn{5}{|l|}{ Payment method } \\
\hline Hourly payment & $111(35.5)$ & $202(64.5)$ & 1.00 & 1.00 \\
\hline Piece rate payment & $58(53.2)$ & $51(46.8)$ & $2.07(1.33-3.21)$ & $2.01(1.23-3.28)^{*}$ \\
\hline \multicolumn{5}{|l|}{ Training on issue of ergonomics } \\
\hline Yes & $11(64.7)$ & $6(35.3)$ & 1.00 & \\
\hline No & $158(39.1)$ & 247 (60.9) & $2.86(1.04-7.90)$ & \\
\hline
\end{tabular}

AOR: adjusted odds ratio, COR: crude odd ratio, ETB: Ethiopian Birr, US: United States, ${ }^{*} P$ value $<0.05,{ }^{* *} P$ value $<0.001$. 
TABLE 7: Multivariate analysis for factors associated with hands/wrist MS disorders among sewing machine operators in Galan City, Oromia Regional State, Eastern Ethiopia, 2012.

\begin{tabular}{|c|c|c|c|c|}
\hline \multirow{2}{*}{ Category of variables } & \multicolumn{4}{|c|}{ Hand/wrist disorder } \\
\hline & Yes $n(\%)$ & No $n(\%)$ & COR $(95 \% \mathrm{CI})$ & $\operatorname{AOR}(95 \% \mathrm{CI})$ \\
\hline \multicolumn{5}{|l|}{ Sex } \\
\hline Male & $31(59.6)$ & $21(40.4)$ & $2.79(1.9-6.4)$ & $2.9(1.3-6.4)^{*}$ \\
\hline Female & $128(34.6)$ & $242(65.4)$ & 1.00 & 1.00 \\
\hline \multicolumn{5}{|l|}{ Educational level } \\
\hline Illiterate & $18(40.0)$ & $27(60.0)$ & $0.60(0.25-1.41)$ & \\
\hline Primary school & $56(41.5)$ & $79(58.5)$ & $0.64(0.32-1.29)$ & \\
\hline Secondary school & $63(31.5)$ & $137(68.5)$ & $0.41(0.21-0.82)$ & \\
\hline Higher education & $22(52.4)$ & $20(47.6)$ & 1.00 & \\
\hline \multicolumn{5}{|l|}{ Monthly salary } \\
\hline$<700$ ETB $(<35.5$ US dollar $)$ & $35(25.4)$ & $103(74.6)$ & $0.26(0.11-0.58)$ & $0.34(0.14-0.85)^{*}$ \\
\hline 700-900 ETB (35.5-45.5US dollar) & $106(42.1)$ & $146(57.9)$ & $0.56(0.26-1.18)$ & $0.66(0.28-1.52)$ \\
\hline$>900$ ETB (>45.5 US dollar) & $18(56.3)$ & $14(43.7)$ & 1.00 & 1.00 \\
\hline \multicolumn{5}{|l|}{ Year of service in garment } \\
\hline $1-5$ years & $86(31.8)$ & $184(68.1)$ & 1.00 & 1.00 \\
\hline $6-10$ years & $50(42.4)$ & $68(57.6)$ & $1.57(1.00-2.45)$ & $1.14(0.70-1.86)$ \\
\hline $11-15$ years & $6(54.5)$ & $5(45.5)$ & $2.56(0.76-8.64)$ & $1.83(0.47-7.03)$ \\
\hline$\geq 16$ years & $17(73.9)$ & $6(26.1)$ & $6.06(2.30-15.91)$ & $4.09(1.48-11.24)^{*}$ \\
\hline \multicolumn{5}{|l|}{ Physical activities } \\
\hline None & $130(36.7)$ & $224(63.3)$ & $1.57(0.64-3.84)$ & $3.41(1.11-10.44)^{*}$ \\
\hline Once per week & $18(62.1)$ & $11(37.9)$ & $4.44(1.41-13-97)$ & $5.34(1.44-19.76)^{*}$ \\
\hline Two times per week & $4(30.8)$ & $9(69.2)$ & $1.20(0.28-5.20)$ & $1.26(0.24-6.41)$ \\
\hline$\geq 3$ times per week & $7(26.9)$ & $19(73.1)$ & 1.00 & 1.00 \\
\hline \multicolumn{5}{|l|}{ Smoking behaviour } \\
\hline None & $139(34.9)$ & $256(64.8)$ & 1.00 & \\
\hline Past smoker & $10(71.4)$ & $4(28.6)$ & $4.60(1.41-14.95)$ & \\
\hline Current smoker & $10(76.90$ & $3(23.1)$ & $6.13(1.66-22.67)$ & \\
\hline \multicolumn{5}{|l|}{ Employment status } \\
\hline Temporary & $18(72.0)$ & $7(28.0)$ & $4.66(1.90-11.44)$ & $3.39(1.24-9.25)^{*}$ \\
\hline Permanent & $141(35.5)$ & $256(64.5)$ & 1.00 & 1.00 \\
\hline \multicolumn{5}{|l|}{ Payment method } \\
\hline Hourly payment & $102(32.6)$ & $211(67.4)$ & 1.00 & 1.00 \\
\hline Piece rate payment & $57(52.3)$ & $52(47.7)$ & $2.26(1.45-3.53)$ & $1.78(1.08-2.93)^{*}$ \\
\hline \multicolumn{5}{|l|}{ Training on health and safety } \\
\hline Yes & $11(64.7)$ & $6(35.3)$ & 1.00 & \\
\hline No & $148(36.5)$ & $257(63.5)$ & $3.18(1.15-8.78)$ & \\
\hline
\end{tabular}

AOR: adjusted odds ratio, COR: crude odd ratio, ETB: Ethiopian Birr, US: United States, ${ }^{*} P$ value $<0.05$.

The increment of wages of employees in this study setting was depending on their year of service in the same industry. The chance of having to develop work related MS disorders could be higher among highly paid employees than those who were paid less. Employees with longer years of service ( $\geq 16$ years) in garment industry were about 4 times more likely to develop elbow/forearm and hand/wrist disorder than employees who had short (1-5 years) years of service, $[\mathrm{AOR}=4.70,95 \% \mathrm{CI}: 1.55-13.02]$ and $[\mathrm{AOR}=4.09$, 95\% CI: 1.48-11.24], respectively. This reveals that operating sewing machine for longer years was strongly associated with increased work related elbow and hand/wrist MS disorders. This finding was in agreement with the study conducted in the Los Angeles, Turkey, Iran, and Denmark [5, 7, 11, 17].
Habits of doing physical exercise had significant association with work related elbow/forearm and hand/wrist MS disorders. Employees who had no habits of doing physical exercises were about 3 up to 5 times more likely to develop hand/wrist and elbow/forearm disorder than workers doing physical exercise for more than three times per week [AOR = 3.41, 95\% CI: $1.11-10.44]$ and [AOR $=5.02$, 95\% CI: $1.57-$ 16.05], respectively. However, those practicing once per week were more likely to develop elbow/forearm and hand/wrist disorder than those practicing more than three times per week. This finding was comparable with a study conducted among workers of video display unit in Finland [18].

In contractual agreement of employment, temporary workers (definite period contract agreement) were 3.39 times 
more likely to develop hand/wrist MS disorders than permanent (indefinite period) workers. However, the Ethiopian labour proclamation number 377/2003, under article 9, 10 stated that "Any contract of employment should be deemed to have been concluded for an indefinite period except for working activates require definite period contract agreement." This finding has also exceeded the standard set in Ethiopian labour proclamation number 377/2003 which states that "The time during which a worker actually performs work or avails herself/himself for work in accordance with law, collective agreement or work rules shall not exceed eight hour a day or forty-eight hour a week" [10].

The payment method affects the prevalence of elbow/forearm and hand/wrist MS disorders among sewing machine operators of garment industries in the study area. Employees with payment method by piece rate were about 2 times more likely to develop elbow/forearm and hand/wrist disorders than those who were paid by hourly rate [AOR $=2.01,95 \%$ CI: $1.23-3.28]$ and [AOR $=1.78$, 95\% CI: $1.08-$ 2.93], respectively. This might be due to the reason that workers increase their speed of work to get more payment. This finding was in agreement with the study conducted in Los Angeles, USA, among sewing machine operators [15].

Generally, there is high prevalence of elbow/forearm and hand/wrist MS disorders among sewing machine operators in the study area. The independent variables such as monthly salary, years of service, physical activities, employment status, and methods of payment had statistically significant association with the occurrence of work related elbow/forearm and hand/wrist MS disorders. Promoting worker involvement in efforts to improve workplace conditions is a critical element in organization process to enhance worker motivation/job satisfaction, added problem solving capabilities, and greater knowledge of work experiences.

Moreover, training is an essential element for any effective safety and health program to recognize workplace risk factors associated with MS disorders and to understand general methods for controlling them and identify the signs and symptoms of MS disorders that may result from exposure to organizational and environmental factors. Furthermore, this study suggested that previous medical history of MS disorders and systemic illness, piece rate work, and a length of working hours per day were key issues which require specific interventions to deal with. Therefore, concerned body gives special attention to prevent and control work related elbow/forearm and hand/wrist MS disorders in garment industries through proper occupational health and safety policy implementation.

\section{Conflict of Interests}

The authors have declared that no conflict of interests exists.

\section{Authors' Contribution}

Ararso Tafese conceived the study and Wakjira Kebede Deyyas developed the proposal and both authors conducted the study and participated in the data analysis, interpretation of the results, and preparation of the paper. Both authors read and approved the final version of the paper.

\section{Acknowledgments}

The authors would like to acknowledge Oromia Regional Social and Labour Affairs Agency for financial support. Their thanks are also due to the owner of two garment industries for volunteering to participate in the study and to all the study participants for their participation in the study.

\section{References}

[1] International Labour Office, "ILO introductory report: global trends and challenges on occupational safety and health," in Proceedings of the 19th World Congress on Safety and Health at Work, Istanbul, Turkey, 2011.

[2] ILO, "Promoting jobs, protecting people: Safety and health at work," March 2013.

[3] V. Woods, "Work-related musculoskeletal health and social support," Occupational Medicine, vol. 55, no. 3, pp. 177-189, 2005.

[4] WHO, Global Strategy on Occupational Health for All the Way to Health at Work Recommendation of the Second Meeting of the WHO Collaborating Centers in Occupational Health, WHO, Beijing, China, 1994.

[5] L. Punnett, J. M. Robins, D. H. Wegman, and W. M. Keyserling, "Soft tissue disorders in the upper limbs of female garment workers," Scandinavian Journal of Work, Environment and Health, vol. 11, no. 6, pp. 417-425, 1985.

[6] U. Berberoǧlu and B. Tokuç, "Work-related musculoskeletal disorders at two textile factories in Edirne, Turkey," Balkan Medical Journal, vol. 30, no. 1, pp. 23-27, 2013.

[7] V. Kalinkara, N. Çekal, I. Akdoğan, and N. Kacar, "Anthropometric measurements related to the workplace design for female workers employed in the textiles sector in Denizli, Turkey," Eurasian Journal of Anthropology, vol. 2, no. 2, pp. 102-111, 2011.

[8] A. Kaergaard and J. H. Andersen, "Musculoskeletal disorders of the neck and shoulders in female sewing machine operators: prevalence, incidence, and prognosis," Occupational and Environmental Medicine, vol. 57, no. 8, pp. 528-534, 2000.

[9] G. H. Schierhout, J. E. Meyers, and R. S. Bridger, "Work related musculoskeletal disorders and ergonomic stressors in the South African workforce," Occupational and Environmental Medicine, vol. 52, no. 1, pp. 46-50, 1995.

[10] MOLSA, "Proclamation No. 377/2003, ADDIS ABABA, 2453," February 2004.

[11] I. Kuorinka, B. Jonsson, A. Kilbom et al., "Standardised Nordic questionnaires for the analysis of musculoskeletal symptoms," Applied Ergonomics, vol. 18, no. 3, pp. 233-237, 1987.

[12] D. W. Hosmer, S. Lemesshow, and R. X. Strurdivant, Applied Logestic Regression USA, John Wiley \& Sons, New York, NY, USA, 2013.

[13] P. W. Buckle and J. J. Devereux, "The nature of work-related neck and upper limb musculoskeletal disorders," Applied Ergonomics, vol. 33, no. 3, pp. 207-217, 2002.

[14] M. Aptel, A. Aublet-Cuvelier, and J. C. Cnockaert, "Workrelated musculoskeletal disorders of the upper limb," Joint Bone Spine, vol. 69, no. 6, pp. 546-555, 2002. 
[15] BLS, National \& International Statistics for Carpal Tunnel Syndrome and Repetitive Strain Injuries of the Upper Extremity, U.S. Department of Labor, 2002.

[16] M. Masih, M. Aghili, H. Asilian, and P. Poursafa, "Evaluation of musculoskeletal disorders in sewing machine operators of a shoe manufacturing factory in Iran," The Journal of the Pakistan Medical Association, vol. 62, no. 3, pp. S20-25, 2012.

[17] S. Blader, U. Barck-Holst, S. Danielsson et al., "Neck and shoulder complaints among sewing-machine operators," Applied Ergonomics, vol. 22, no. 4, pp. 251-257, 1991.

[18] T. Korhonen, R. Ketola, R. Toivonen, R. Luukkonen, M. Häkkänen, and E. Viikari-Juntura, "Work related and individual predictors for incident neck pain among office employees working with video display units," Occupational and Environmental Medicine, vol. 60, no. 7, pp. 475-482, 2003. 


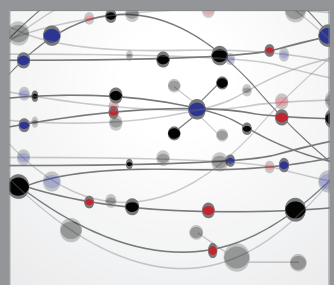

The Scientific World Journal
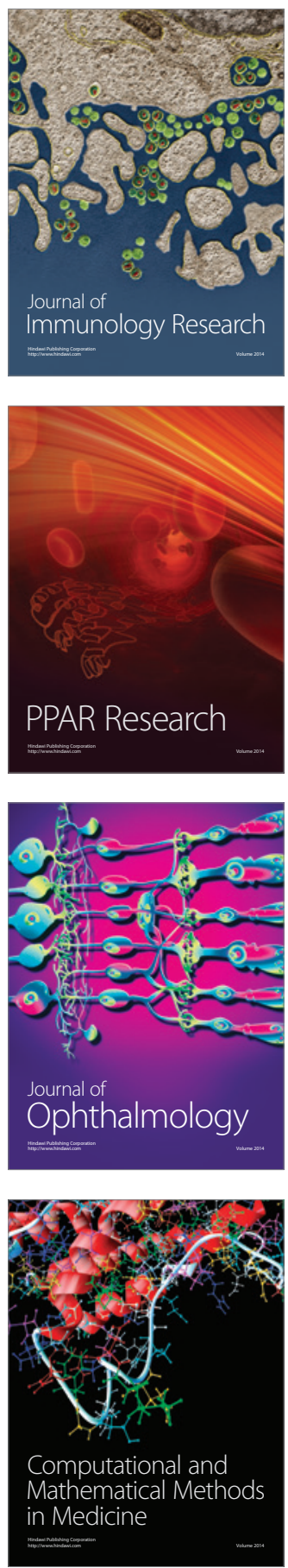

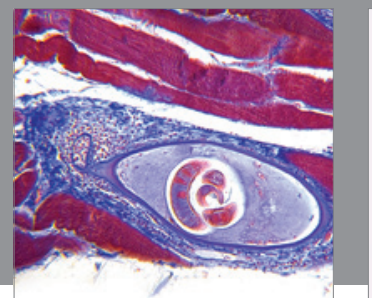

Gastroenterology

Research and Practice
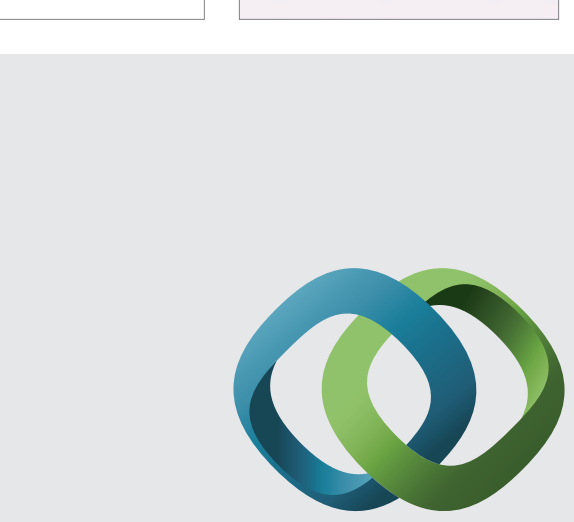

\section{Hindawi}

Submit your manuscripts at

http://www.hindawi.com
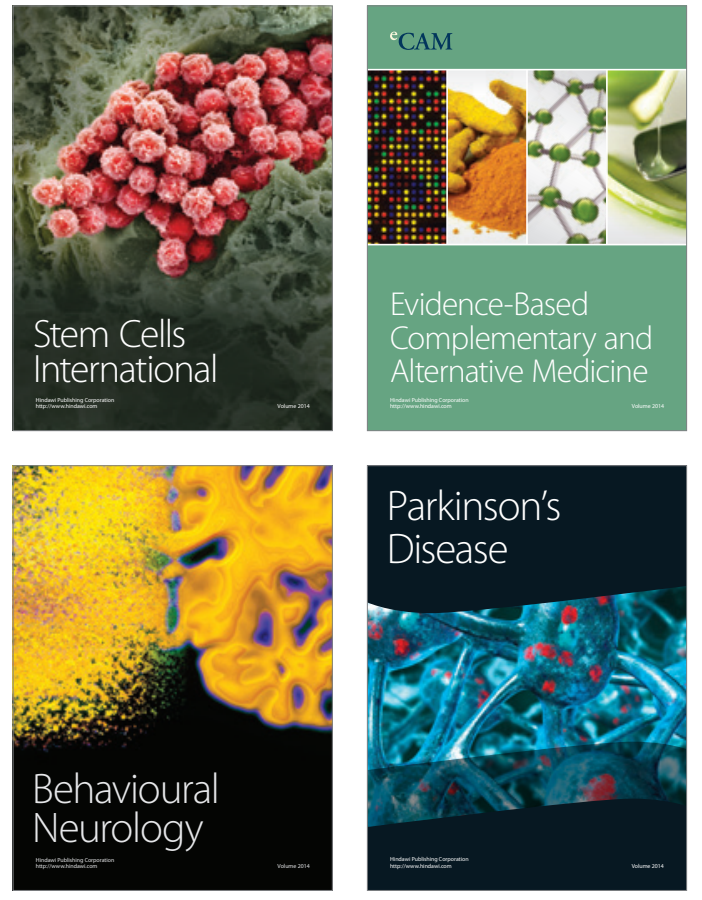
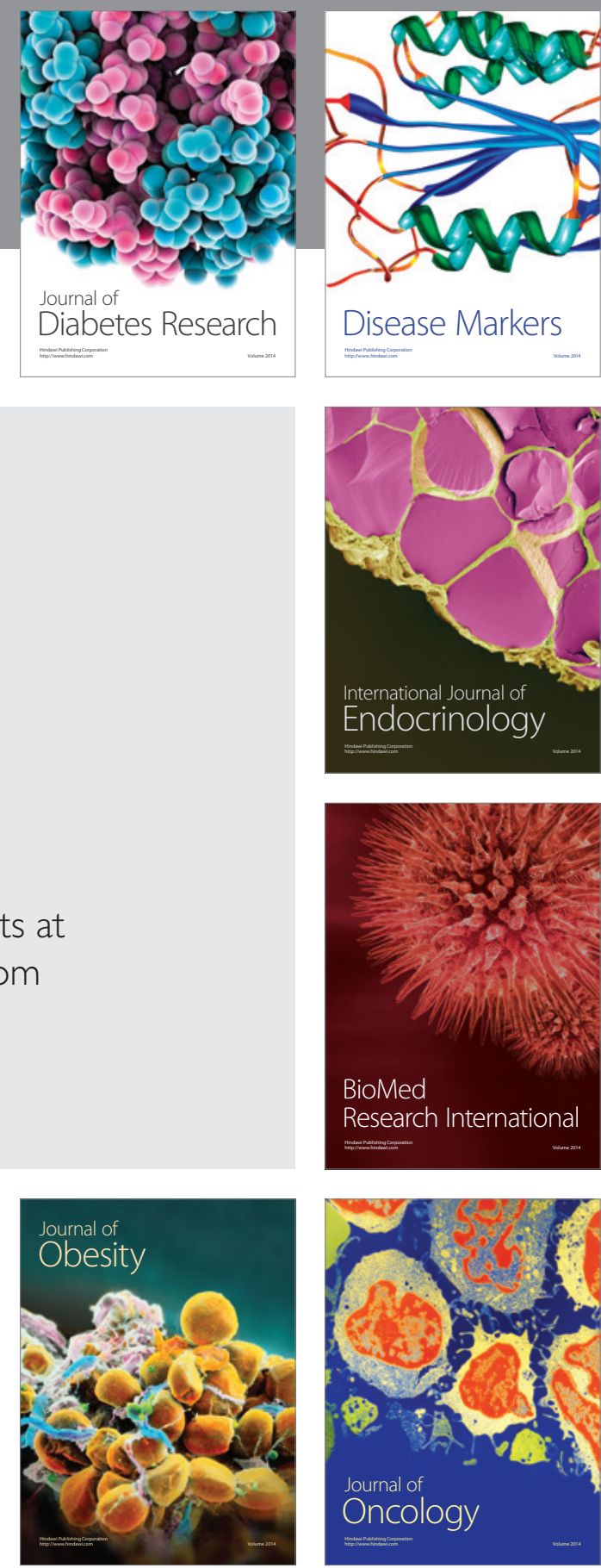

Disease Markers
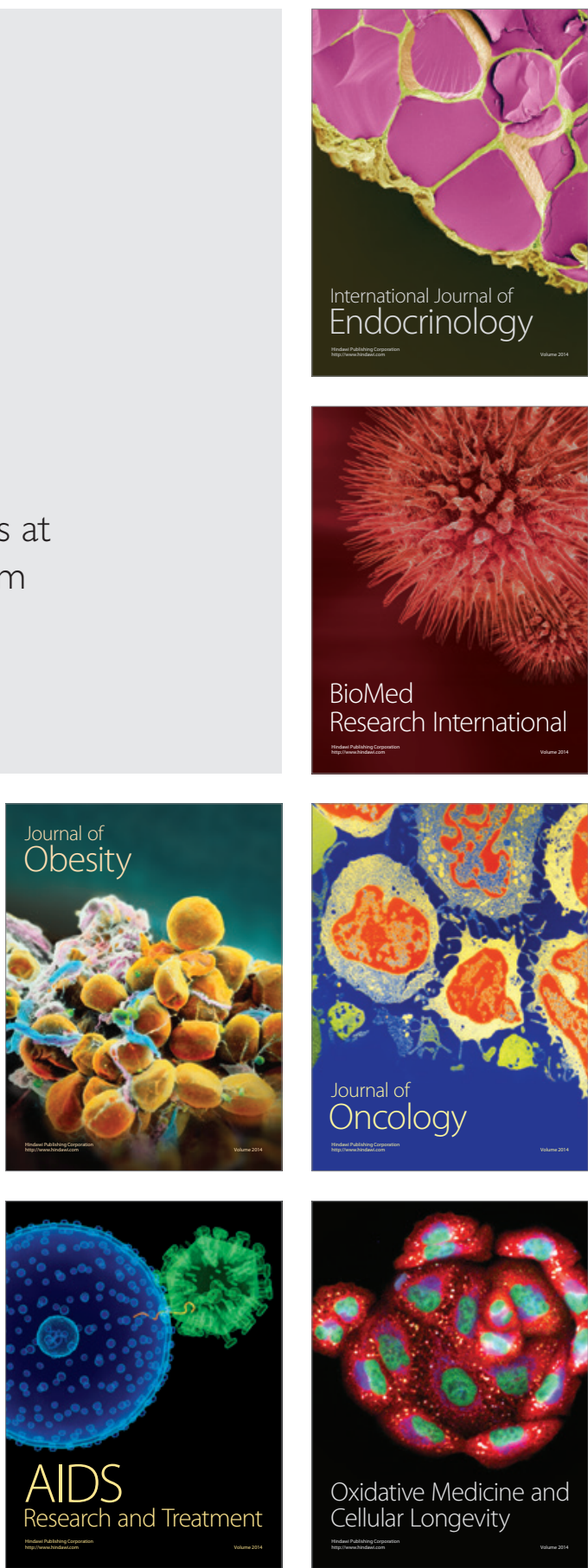